\title{
Toughening of PMMA by short poly(p-phenylene-2,6-benzobisoxazole) fibers
}

\author{
M. Zboncak ${ }^{1 *}$, J. Jancar ${ }^{1,2}$ \\ ${ }^{1}$ Central European Institute of Technology, Brno University of Technology, Purkynova 123, 61200 Brno, Czech Republic \\ ${ }^{2}$ Faculty of Chemistry, Institute of Materials, Brno University of Technology, Purkynova 118, 61200 Brno, \\ Czech Republic
}

Received 11 January 2018; accepted in revised form 29 March 2018

\begin{abstract}
We report on unique enhancement of fracture resistance of poly(methyl methacrylate) (PMMA) using short and low bending modulus poly( $p$-phenylene-2,6-benzobisoxazole) (PBO) fibers. While no significant effect of the PBO fibers on stiffness and strength was observed, the strain at break and fracture energy were enhanced substantially. The in situ observations of damage development during the tensile tests showed that the additional extrinsic toughening mechanisms consists of homogenous distribution of micro-cracking and delocalization of the deformation sites to the whole volume of the sample with micro-cracks bridged by the entangled PBO fiber mesh. Employing unique toughening mechanisms of PBO fiber network in hybrid PMMA/CF/PBO composites containing both carbon (CF) and PBO fibers lead to simultaneous enhancement of stiffness, strength and toughness suitable for wide range of engineering applications.
\end{abstract}

Keywords: polymer composites, reinforcements, mechanical properties

\section{Introduction}

Short fiber reinforced thermoplastics (SFRT) represent lightweight engineering materials for injection molded or compression molded components with complex shapes desired for large volume applications like automotive. Mechanical properties of SFRT are controlled by fiber mechanical properties, volume fraction, their aspect ratio, orientation and adhesion to the matrix [1-6]. Most frequently, stiff and brittle glass (GF) or carbon (CF) fibers are used as reinforcement for a wide range of thermoplastic polymers. Forces generated by the viscous melt thermoplastic matrix, fiber-fiber interactions and fiber-machine contact during melt blending or processing result in fiber length degradation. The degraded fiber length reduces the extent of possible stress transfer into the fibers and increases the number of fiber ends acting as defects for stress concentration $[1,7]$. As a result, mechanical properties of SFRT may become severely compromised.

To obviate the fiber length degradation during melt mixing and processing, various natural [8] or synthetic organic low bending modulus fibers such as Kevlar $[9,10]$, poly(ethylene terephthalate) (PET) [11] or polyimide $[12,13]$ were used in various polymer matrices to improve their mechanical properties. While the length of organic fibers is preserved during melt compounding, their matrix/fiber interfacial adhesion and alignment are severally compromised. This makes brittle short fibers the major reinforcement type in composite technology.

The poly(p-phenylene-2,6-benzobisoxazole) (PBO) is a highly crystalline aromatic heterocyclic polymer used to produce high performance fibers [14-16] exhibiting extraordinary high tensile modulus and strength among other organic fibers $[17,18]$. Despite 
their unique mechanical properties, their use in SFRT is rather rare. Low bending stiffness, poor environmental stability and interfacial adhesion are among the primary reasons for this state of the art.

In addition to structurally desired stiffness, fracture toughness is often decisive for the selection of SFRT in many applications. The fracture resistance of a fiber reinforced composite has contributions from intrinsic mechanisms operating at the molecular scale ahead of the crack tip and extrinsic mechanisms related to the architecture of the reinforcement which operate behind the crack tip and help to sustain the materials load bearing capability after crack initiation $[19,20]$.

Initiation and propagation of a crack is a function of temperature, stress, sample geometry, matrix molecular weight, or strain rate [21-24]. In the case of heterogeneous SFRT, fibers play an important role in crack initiation and generating the extrinsic deformation mechanisms stabilizing micro-crack growth and enhancing the extent of energy dissipated during fracture. Moreover, they can change the failure mode from the brittle/catastrophic to the quasi stable one. These mechanisms include the matrix-fiber debonding, crack bifurcation, deflection, fiber fracture, fiber pull-out, crack bridging or delamination [25-33]. Friedrich [34] proposed theoretical model expressing the critical strain energy release rate $\left(G_{\text {IC }}\right)$ for unidirectional short fiber reinforced composites. This model accounts contribution from fiber breaking, de-bonding and pulling-out the fibers and the matrix fracture. In order to account for fiber orientation and to eliminate the singularity of the $G_{\mathrm{IC}}$ for $v_{\mathrm{F}}=0$, this model was modified by Jancar et al. [35]. Both models assume that only fibers oriented in the direction of the loading can be pulled-out and contribute to toughening significantly.

This is a reasonable assumption in the case of rigid brittle fibers. However, the low bending stiffness ductile fibers can contribute to energy dissipation even when their orientation deviates from the loading direction significantly. In addition, initiation of multiple micro-cracks further from the main crack plane expands the deformation zone enhancing the extent of mechanical energy upon failure significantly. It was shown that long-fiber (LFT) or entangled non-woven glass fiber mat (GMT) in thermoplastic matrix can expand damage zone considerably [36-41]. Deformation zone can be expanded via entangled/adjacent fibers as far as tens of millimeters from propagating crack, however, after reaching critical size of the deformation zone, a significant drop in force is observed $[38,39]$. These materials find their usage in automotive applications as various large parts [42].

Here, we report on unique contribution of low bending stiffness-high tensile modulus PBO fibers to the fracture resistance of PMMA and its SFRT in uniaxial tension. Mechanical properties of PMMA/PBO composite characterized by fiber network created during melt compounding are compared with composites reinforced with conventional brittle fibers types used in composite technology (glass, carbon). To account for the structural parameters expressing fiber orientation and interfacial adhesion for investigated systems, we introduce an effective fiber length ( $\left.L_{\mathrm{Eff}}\right)$ as the single structural variable capturing the composition dependence regardless of the type of fibers studied. Simultaneous measurement of the stress-strain curve and observation of damage development in the view field of the confocal laser scanning microscope (CLSM) allowed to identify the additional extrinsic toughening mechanisms introduced by the PBO fibers and their relative contribution to the enhancement of the overall fracture energy. In addition, we used PBO toughening mechanisms in hybrid PMMA/CF/PBO composite containing 10 vol\% of both fiber types (carbon and PBO) to enhance stiffness, strength and fracture energy of this composite.

\section{Experimental}

\subsection{Materials}

Poly-methyl methacrylate (PMMA) PLEXIGLAS ${ }^{\circledR}$ $6 \mathrm{~N}$ (Evonik, Germany) was used as matrix $\left(M_{\mathrm{n}}=\right.$ $\left.4.6 \cdot 10^{4} \mathrm{~g} / \mathrm{mol}, M_{\mathrm{w}} / M_{\mathrm{n}}=1.8\right)$. Short PBO fibers ZYLON ${ }^{\circledR}$ AS (Toyobo, Japan), glass fibers CHOPVANTAGE HP ${ }^{\circledR} 3540$ (PPG Industries Fiber Glass EMEA, Netherlands) and carbon fibers SIGRAFIL ${ }^{\circledR}$ C30 S003 PUT (SGL Group, Germany) were used as the reinforcement. Fibers were used as received without any additional surface treatment and were vacuum

Table 1. Mechanical properties of the PMMA matrix and the reinforcing fibers.

\begin{tabular}{|l|r|r|c|c|c|c|}
\hline & $\begin{array}{c}\boldsymbol{E} \\
{[\mathbf{G P a}]}\end{array}$ & $\begin{array}{c}\boldsymbol{\sigma} \\
{[\mathbf{M P a}]}\end{array}$ & $\begin{array}{c}\boldsymbol{\varepsilon} \\
{[\mathbf{\%}]}\end{array}$ & $\begin{array}{c}\boldsymbol{L}_{\mathbf{0}} \\
{[\mathbf{m m}]}\end{array}$ & $\begin{array}{c}\boldsymbol{D} \\
{[\boldsymbol{\mu m}]}\end{array}$ & $\begin{array}{c}\boldsymbol{L}_{\mathbf{0}} / \boldsymbol{D} \\
{[-]}\end{array}$ \\
\hline PMMA & 1.8 & 49.7 & 3.5 & - & - & - \\
\hline GF & 73.0 & 3600.0 & 4.8 & 3.8 & 10 & 380 \\
\hline CF & 240.0 & 4000.0 & 1.7 & 3.0 & 7 & 430 \\
\hline PBO & 180.0 & 5800.0 & 3.5 & 3.5 & 12 & 290 \\
\hline
\end{tabular}

$E$ is the tensile modulus, $\sigma$ is the tensile strength, $\varepsilon$ is the ultimate tensile strain, $L_{0}$ is the initial fiber length and $D$ is the diameter. 
dried at $100^{\circ} \mathrm{C}$ for 2 hours prior to mixing into the matrix. Mechanical properties of the polymer matrix and the fibers are listed in the Table 1.

\subsection{Sample preparation}

Composites were prepared by melt compounding employing the $55 \mathrm{~cm}$ batch Mixer W 50 EHT (Brabender OHG, Germany) electrically heated with 2 roller blades. The PMMA was plasticized for $2 \mathrm{~min}$ utes at $230^{\circ} \mathrm{C}$ at $40 \mathrm{rpm}$. Then, the desired amount of fibers was gradually added into the liquid matrix and mixed for 2 minutes. Fiber volume fraction is $10,20,30$ and $40 \mathrm{vol} \%$ for all fiber types investigated (marked as 0.1-0.4). The neat PMMA used as a reference material underwent the same preparation protocol. Compounds were compression molded into $150 \mathrm{~mm} \times 150 \mathrm{~mm}$ sheets $\sim 0.7 \mathrm{~mm}$ thick by the hotpress LPB 300 (Fontijne Grotnes B.V., Netherlands). Compounds were preheated for 10 minutes at $190^{\circ} \mathrm{C}$ and then compression molded with the clamping force of $300 \mathrm{kN}$, held for 2 minutes followed by cooling to the laboratory temperature at the cooling rate of $40 \mathrm{~K} \cdot \mathrm{min}^{-1}$. Test specimens were cut out from the compression molded sheets by water-jet.

\subsection{Mechanical testing}

Tensile properties were determined using the Z010 tensile tester (Zwick-Roell, Germany) at laboratory temperature and the cross-head speed of $1 \mathrm{~mm} / \mathrm{min}$. The standard ISO 527 5A test specimens with gauge length of $25 \mathrm{~mm}$ were used. Minimum 5 specimens were used for each composition and their average properties are reported here. Fracture energy (fracture work) is determined as energy under the stress-strain curve. The LabTest 4.0055-H micro tensile tester (Labor Tech, Czech Republic) was used in the combination with LEXT OLS 3000 Confocal Laser Scanning Microscope (Olympus, Japan) to investigate fracture process of PMMA/PBO composite in course of deformation at room temperature and cross-head speed $1 \mathrm{~mm} / \mathrm{min}$.

\subsection{Determination of fiber content and structure of composite}

The TGA Q500 (TA Instruments, USA) was utilized to determine exact fiber volume fraction $\left(v_{\mathrm{F}}\right)$ by heating the materials up to $500^{\circ} \mathrm{C}$ under the $\mathrm{N}_{2}$ atmosphere at the heating rate of $50^{\circ} \mathrm{C} / \mathrm{min}$. Confocal laser scanning microscope LEXT OLS 3000 (Olympus, Japan) and scanning electron microscope Zeiss EVO
LS10 (Zeiss, Germany) was used for structural analysis of fracture surfaces, cracks on the sample surfaces and to determine the average fiber orientation and qualitatively assess the matrix-fiber adhesion. Structure of the entangled PBO network was obtained by Soxhlet extraction of the PMMA matrix in acetone and then observed by SEM. Conductive Au-Pt layer was sputtered onto fracture surfaces using the POLARON SC 7640 sputter coater (Quorum Technologies Ltd., UK) to increase conductivity.

\section{Results and discussion}

\subsection{Structure of composites}

SEM micrographs revealed poor interfacial adhesion to the PMMA in all systems investigated systems and the brittle nature of the matrix fracture (Figure 1a, 1b, $1 \mathrm{c}, 1 \mathrm{~d})$. As result of weak interfacial adhesion, pulled out fibers can been seen for investigated composites because sufficient amount of stress cannot be transferred into the fibers and matrix-fiber interface breaks first. While length of glass (GF) and carbon (CF) fibers was reduced significantly (hundreds of micrometers, as measured after TGA of composites by CLSM), poly ( $p$-phenylene-2,6-benzobisoxazole) (PBO) fibers exhibited no length degradation upon sample preparation. Similar length preservation was observed previously for $\mathrm{PBO}$ fibers during melt compounding with elastomer matrix [43]. On the other hand, PBO fibers were spatially organized in an entangled fiber network (Figure 1e) and the partial mechanical degradation of the PBO fibers occurred by the means of forming kink bands (Figure 1f). The kink bands are result of the extensive compression and out-off-axis loads inserted on the fibers during compounding destroying the superstructure of $\mathrm{PBO}$ fibers and decreasing local stiffness of fiber [44-46]. The average PBO fiber length between kink bands is $\sim 30 \mu \mathrm{m}$, diameter of king band is $\sim 15 \mu \mathrm{m}$ with length $5-15 \mu \mathrm{m}$. Entangled PBO fiber network can be thus simplified as stiff fiber parts interconnected by softer and compliant kink bands.

\subsection{Mechanical properties}

As expected, the addition of GF and $\mathrm{CF}$ resulted in an increase of the tensile elastic modulus (Figure 2a) and non-monotonous composition dependence of ultimate strength of PMMA composites (Figure 2b). The growing deviation of the composition dependence of the elastic modulus relative to that of the neat matrix from linearity is caused by fiber misalignment, 


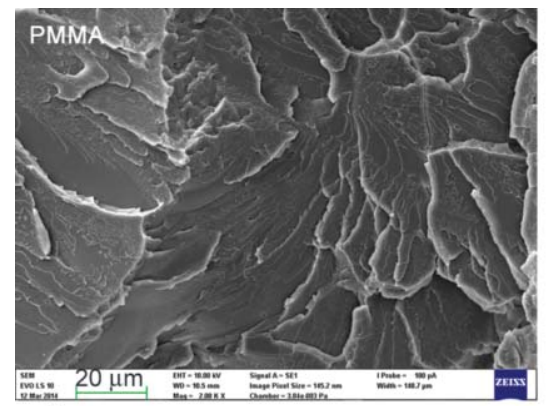

a)

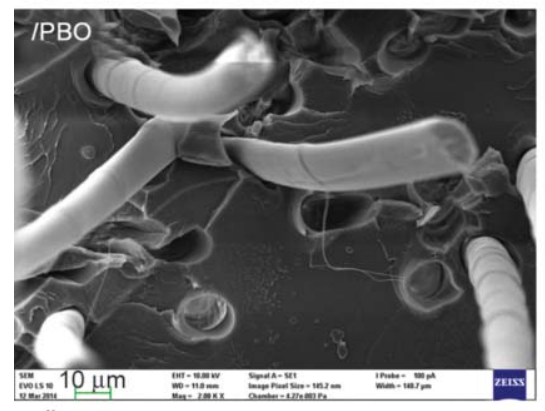

d)

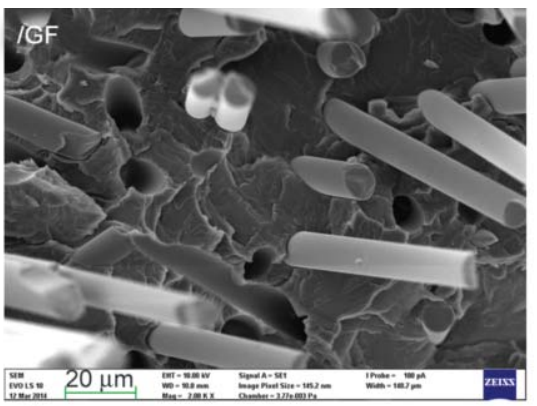

b)

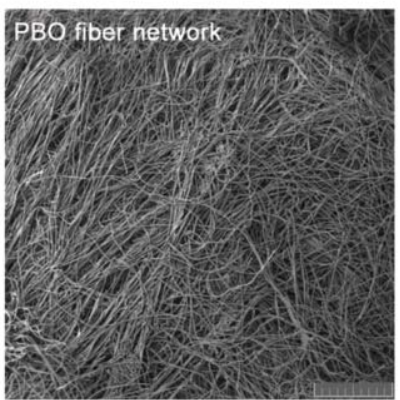

e)

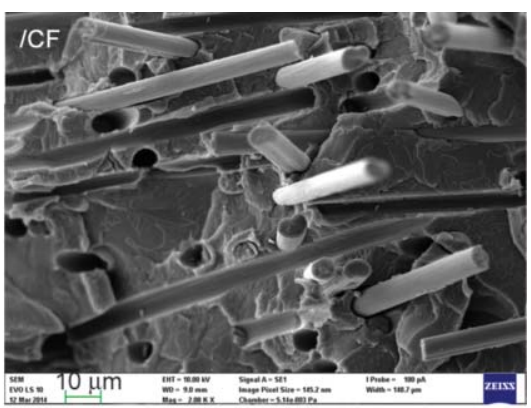

c)

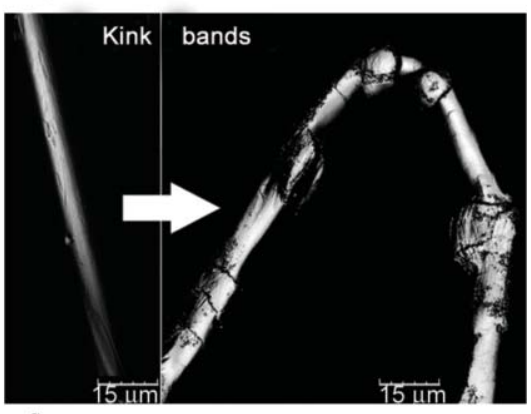

f)

Figure 1. Micrograph of (a) PMMA and (b, c, d) its composites fracture surfaces after tensile test. Fiber type used as a reinforcement is marked in micrographs. (e) Structure of intermingled PBO fiber network in PMMA/PBO composite (scale bar $1 \mathrm{~mm}$ ) and (f) kink bands after melt processing (scale bar $15 \mu \mathrm{m}$ ).

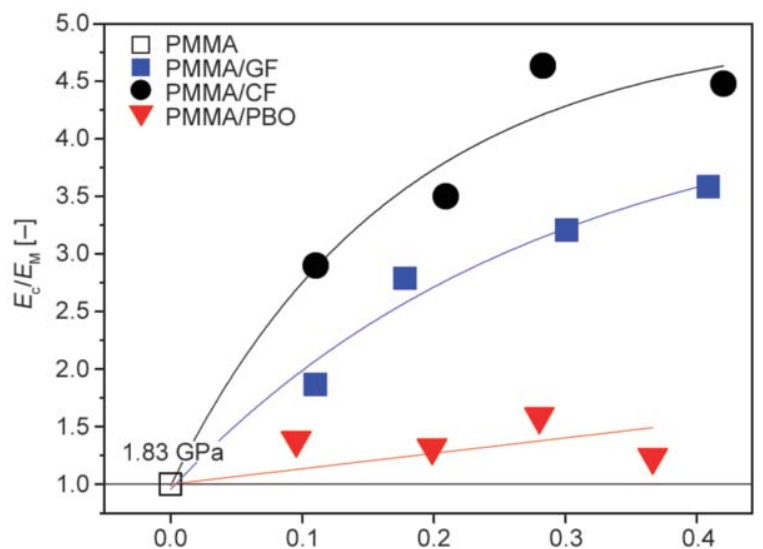

a)

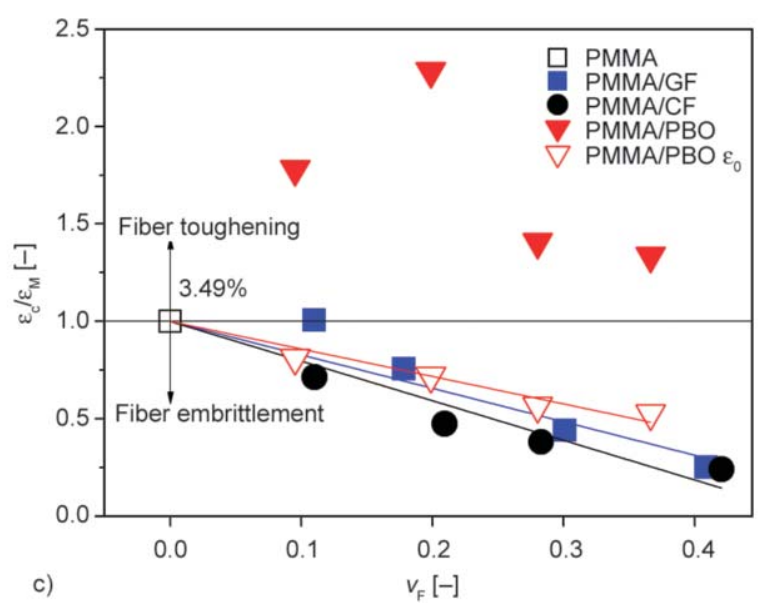

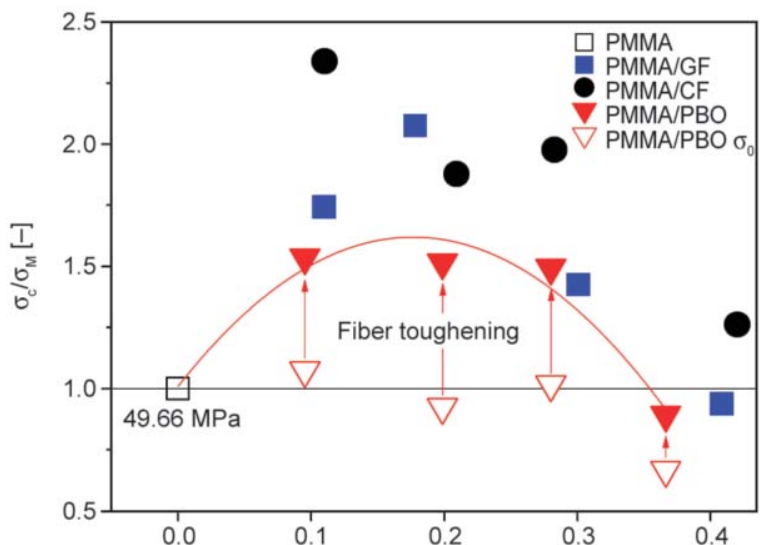

b)

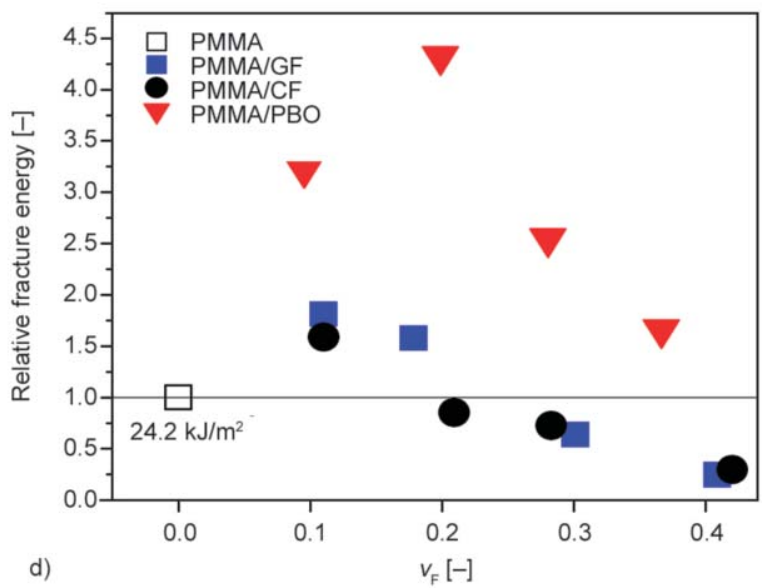

Figure 2. The composition dependence of the (a) relative tensile modulus, (b) relative strength, (c) relative strain and (d) relative fracture energy of composites in uniaxial tension. Parameters $\sigma_{0}$ and $\varepsilon_{0}$ represents values without PBO fiber toughening mechanisms (discussed in Section 3.2.3). Absolute value of mechanical properties for neat PMMA are listed in plots. 
bundling and mechanical length degradation all increasing with $v_{\mathrm{F}}[4,5,47,48]$. The low reinforcing efficiency of the PBO fibers is caused by their weak interfacial adhesion to PMMA as previously reported problematic issue for these fibers [49-52], extensive fiber bending compromising their unidirectional alignment in tensile direction and local plastic deformation expressed by the presence of the kink bands (Figure 1f) decreasing PBO effective fiber length significantly.

Tensile strain (Figure 2c) linearly decreases for investigated brittle fibers with increasing fiber volume fraction as result of fiber embrittlement as number of fiber ends and transversely oriented fibers increases [1]. In comparison with these systems, $\mathrm{PMMA} / \mathrm{PBO}$ ultimate strain is enhanced significantly (by $130 \%$ for PMMA/PBO 0.2) without any catastrophic drop in stress during testing. As a result, the total fracture energy of composite was enhanced significantly (Figure $2 \mathrm{~d}$ ). To our knowledge, we are not aware of similar results for micro $\mathrm{PBO}$ and/or similar fiber types in a polymer matrix. In addition, plastics reinforced with the short PBO fibers are very rare in literature, mainly due to the weak interfacial adhesion, and we have found only limited number of publications dealing with engineering properties of polymer/PBO short fiber composites [43, 49, 53]. Thus, this work can provide experimental data justifying future research on the short PBO fibers toughened thermoplastic composites.

Toughening of brittle thermoplastic matrix by increase of ultimate strain by entangled fiber network was reported by Sun et al. [54]. Their thermoplastic poly(lactic acid) (PLA) filled with polyurethane fiber network shows massive increase in ultimate strain but significant decrease in the strength and modulus when compared to neat PLA. However, toughening mechanisms were not fully elucidated and ascribed to matrix/fiber interfacial failure and stress transfer via multiple entangled fibers. Similar mechanism for enhancing the fracture toughness was also proposed earlier for LFTs and GMTs as being effective in extending the damage zone considerably via mechanisms such as: crack blunting, short and long range matrix-fiber interfacial failure (debonding), fiber pullout and fibrillation of fiber strands [36-41].

\subsubsection{Effective fiber length}

As fiber orientation deviates from the direction of the applied load, the contribution of fiber to the reinforce- ment is reduced $[55,56]$. Here, the tensile modulus is determined at small deformations $(0.05-0.25 \%)$ and it is strictly driven by the structural variables such as fiber orientation and interfacial strength. The semiempirical Halpin-Tsai model (H-T model, Equation (1)) [57] was derived for composites containing discontinuous reinforcement and accounting with the reinforcement's geometry, orientation and stiffness (Equation (2), (3)). The shape parameter ( $\xi$ ) in this model (Equation (3)) takes a geometry of reinforcement and its relative orientation to the external loading into consideration. For systems with varying fiber length and random fiber orientation, we introduce effective fiber length ( $\left.L_{\mathrm{Eff}}\right)$ and/or effective aspect ratio $\left(L_{\mathrm{Eff}} / D\right)$ calculated from the experimentally measured tensile modulus. The $L_{\mathrm{Eff}}$ is calculated as the best fit of the H-T model with experimentally measured tensile modulus via Equation (4):

$$
\frac{E_{\mathrm{C}}}{E_{\mathrm{M}}}=\frac{1+\xi \eta v_{\mathrm{F}}}{1-\eta v_{\mathrm{F}}}
$$

$\eta=\frac{\frac{E_{\mathrm{F}}}{E_{\mathrm{M}}}-1}{\frac{E_{\mathrm{F}}}{E_{\mathrm{M}}}-\xi}$

$\xi=2 \frac{L_{\mathrm{Eff}}}{D}$

$L_{\mathrm{Eff}}=D \frac{v_{\mathrm{F}} E_{\mathrm{C}}\left(E_{\mathrm{M}}-E_{\mathrm{F}}\right)+E_{\mathrm{F}}\left(E_{\mathrm{C}}-E_{\mathrm{M}}\right)}{2\left[E_{\mathrm{M}}\left(E_{\mathrm{M}}-E_{\mathrm{C}}+v_{\mathrm{F}}\left(E_{\mathrm{F}}-E_{\mathrm{M}}\right)\right)\right]}$

In Equations (1)-(4), $E_{\mathrm{C}}, E_{\mathrm{M}}$ and $E_{\mathrm{F}}$ are the tensile elastic moduli of the composite, the neat matrix and fibers, respectively, $\eta$ and $\xi$ are the Halpin-Tsai parameters, $L_{\mathrm{Eff}}$ is effective fiber length projected into the direction of acting force, $D$ is fiber diameter and $v_{\mathrm{F}}$ is fiber volume fraction.

The parameter $L_{\mathrm{Eff}}$ represents the projection of the critical fiber length in the direction of the acting force (unidirectional tension) and the strength of the interfacial adhesion (Figure 3a). Parameter $L_{\text {Eff }}$ decreases as fibers become more misaligned at higher fiber volume fraction or interfacial adhesion becomes weaker (not accounted here since strength of interfacial adhesion between matrix and fiber is kept constant). For the entangled PBO fiber mesh, value of $L_{\mathrm{Eff}}$ decreases down to couple of micrometers (16.9-3.3 $\mu \mathrm{m}$, for $v_{\mathrm{F}}=0.1-0.3$, respectively). Taking into consideration the average length of PBO fiber between kink bands $\sim 30 \mu \mathrm{m}$, such a short effective 

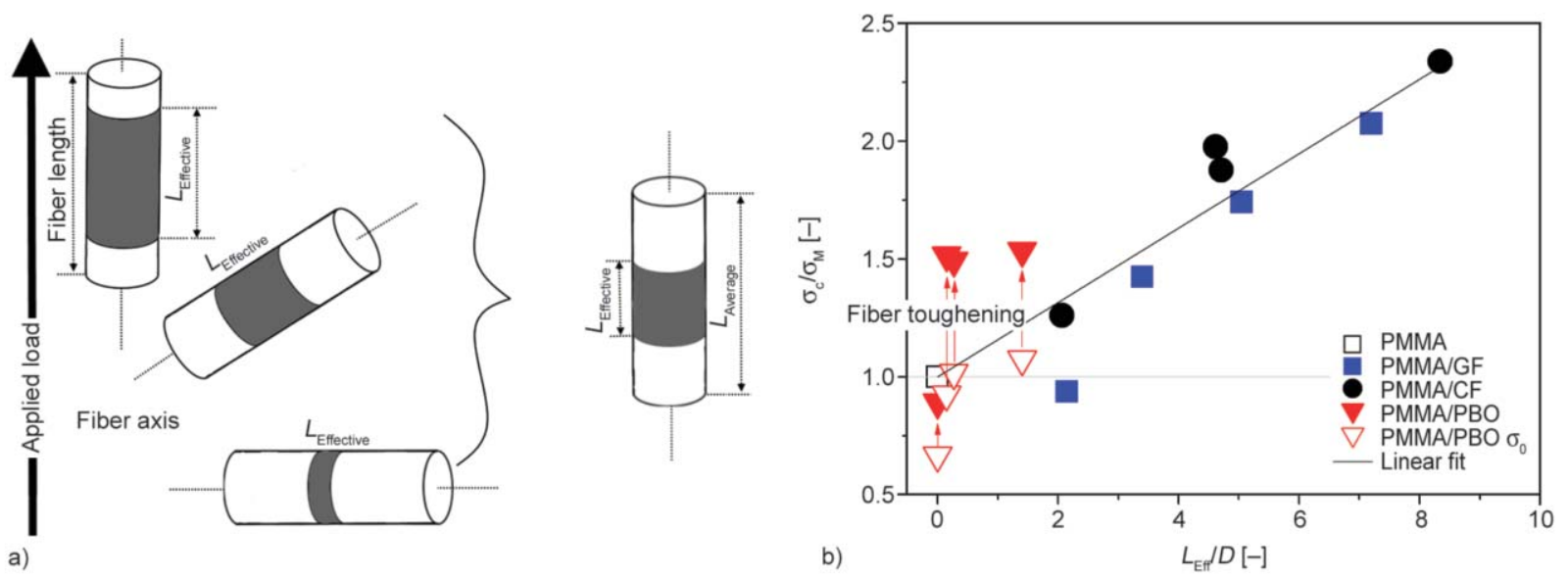

Figure 3. (a) Schematic representation of the effective fiber length $\left(L_{\mathrm{Eff}}\right)$ versus average fiber length. (b) The dependence of the relative tensile strength on the effective aspect ratio. $\sigma_{0}$ (empty symbols) represents values without fiber toughening mechanisms (discussed in Section 3.2.3).

fiber length makes stress transfer highly ineffective, as fiber length is evidently below the critical fiber length as evidenced from the negligible enhancement of tensile modulus (Figure 2a).

With the fiber length degradation and the orientation of fibers becoming more random, the $v_{\mathrm{F}}$ dependences of the relative strength become non-monotonous for the PBO fiber systems or decreasing for systems reinforced with brittle fibers (Figure 2b). However, by plotting the relative strength as a function of the effective aspect ratio $\left(L_{\mathrm{Eff}} / D\right)$, a linear master curve is obtained (Figure $3 b$ ), further supporting the unique role of the parameter $L_{\mathrm{Eff}}$. While strength of the PMMA/PBO composite without the stabilizing PBO fiber toughening mechanisms $\left(\sigma_{0}\right)$ (more detailed discussed in Section 3.2.3) fits this trend quite well, ultimate strength of PMMA/PBO composites deviates from the master curve significantly. This is ascribed to the parameter $L_{\mathrm{Eff}}$ for PBO fibers calculated from Halpin-Tsai model accounting only for the stress transfer reinforcing mechanism. For the PMMA/ PBO composites, ultimate strain and strength are enhanced via multiple toughening mechanisms developed during deformation (discussed further in text).

\subsubsection{Fractography of PMMA/PBO composites}

As expected, the major crack propagated in PMMA, PMMA/CF and PMMA/GF composites, through the cross-section of the sample with a very small crack tip process zone, suggesting extreme strain localization. The crack path is controlled by the ratio between the strength and toughness of the PMMA-fiber interphase compared to those for the matrix and the fiber. For the weak interphase, the crack propagates along the fiber length resulting in the fracture surface characterized by fiber pull-out (Figure 1b, 1c, 1d). This failure process dissipates mechanical energy due to fiber-matrix friction and partial deformation of the fibers causing a fair enhancement of the crack resistance. The contribution of this mechanism to overall fracture toughness is negligible for PMMA/GF and PMMA/CF composites due to fiber misalignment and short fiber length. But this mechanisms prevails in PMMA/Kevlar composites from previous work with sufficiently long and low bending modulus fibers [35]. In addition to the interphase properties, fiber orientation and fiber length play also significant role in the crack deflection, formation of secondary cracks $[28-30,36-38,40,41]$ and the ability to dissipate the mechanical energy farther from the major crack plane via interface failure (debonding). Short length of GF and CF ensures extreme energy localization near the main crack plane. Only very small number of secondary micro-cracks were found by CLSM in the vicinity of the main crack plane and their number was reduced with increasing the fiber volume fraction. In comparison with the investigated brittle fiber composites and neat matrix, PMMA/PBO composites showed formation of significant number of micro-cracks in the entire deformed specimen (Figure 4) and the fracture energy of composites was enhanced significantly.

\subsubsection{In-situ observation of PMMA/РBO deformation}

The tensile tests performed in the view field of the CLSM revealed the peculiarities of the fracture processes in the PMMA/PBO characterized by entangled and kink banded PBO fiber network structure. 


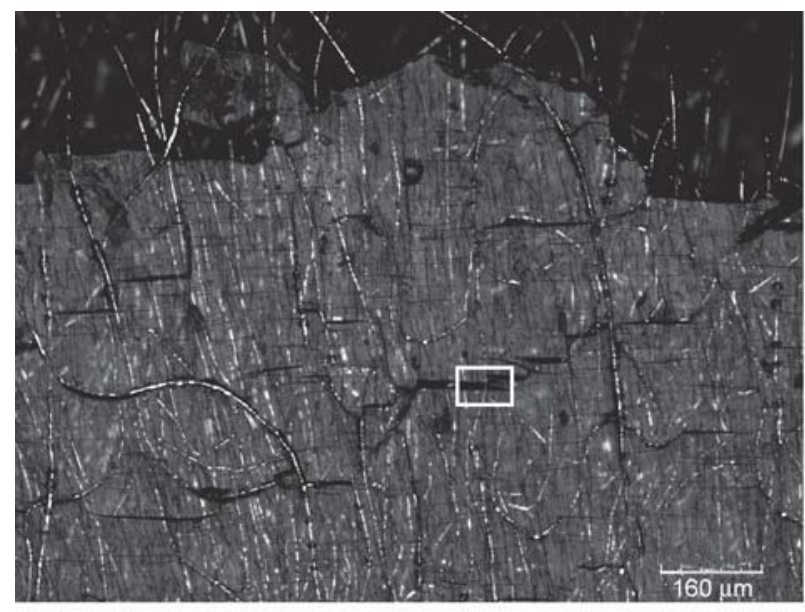

a)

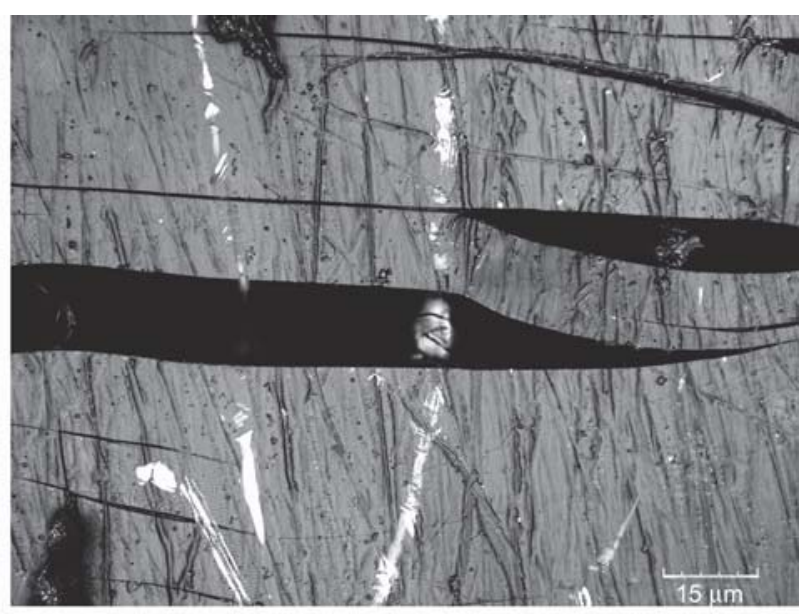

b)

Figure 4. (a) Surface crack morphology in proximity of major crack plane for PMMA/PBO 0.2 sample with marked detail (b) into the PBO bridged micro-crack, scale bar 160 and $15 \mu \mathrm{m}$, respectively.

During the tensile deformation, the entire volume of specimen gauge length participated in the deformation process with the surface morphology characterized by stable micro-cracks growth while preserving the load bearing capability of the composite,
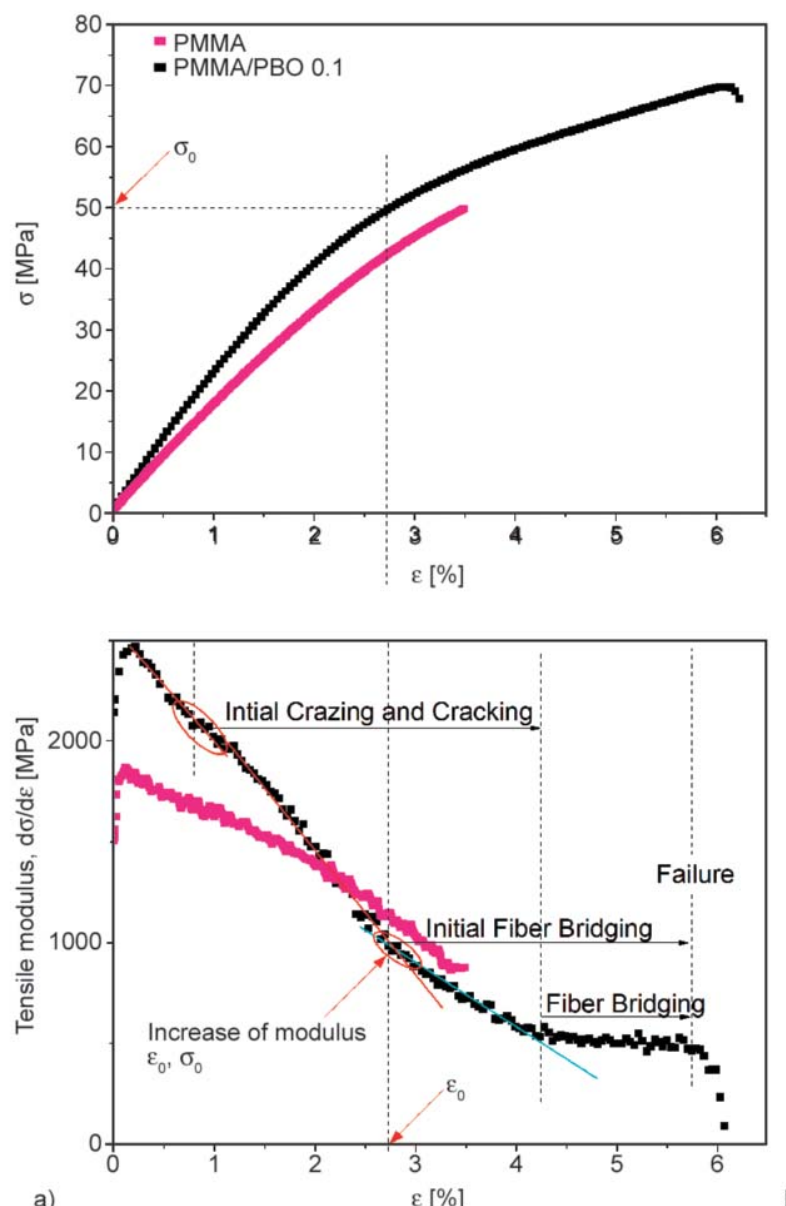

avoiding brittle catastrophic failure. The simultaneous CLSM observation and tensile loading allowed to identify the individual failure steps and to relate them to the strain level at which they occur (Figure 5).
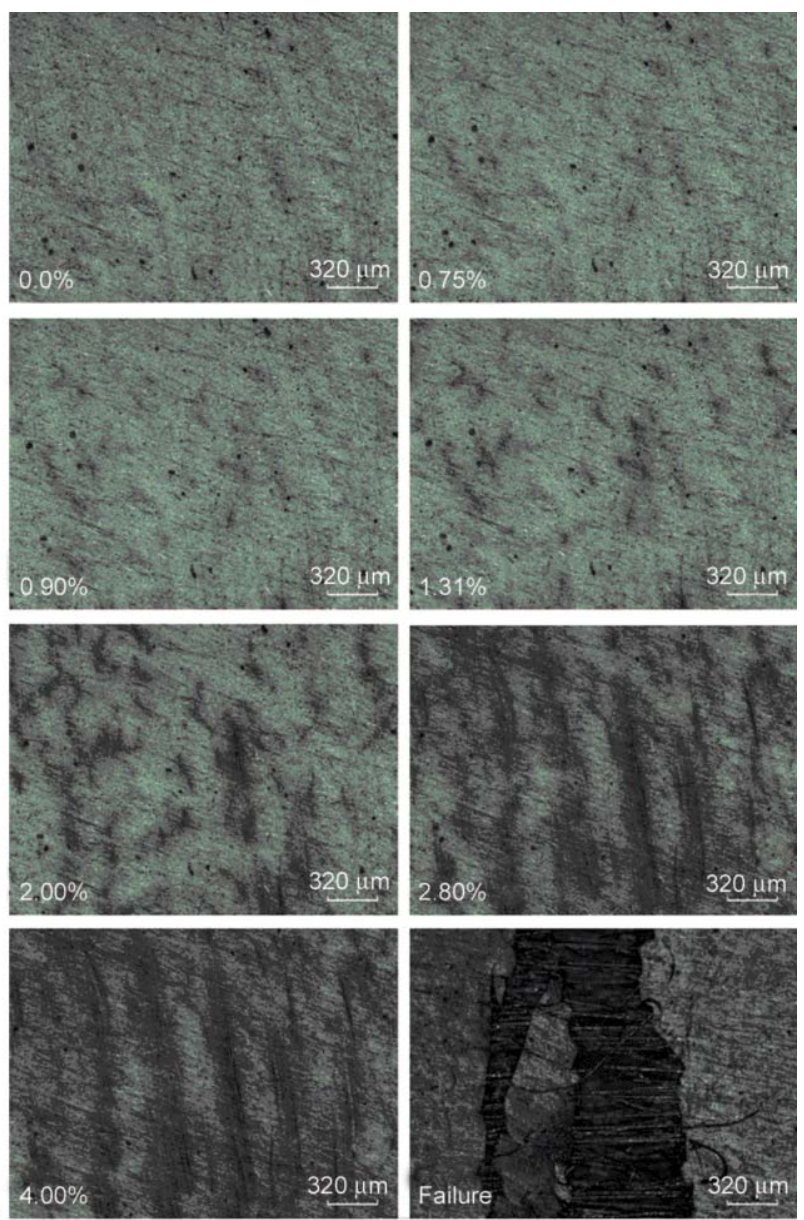

Figure 5. (a) Stress-strain curve for PMMA/PBO 0.1 sample and its differentiation with (b) marked observed area of sample by CLSM during the test. Cracks generation and propagation during tensile test at surface of PMMA/PBO 0.1 sample observed by laser scanning microscopy, magnification $5 \times$, scale bar $320 \mu \mathrm{m}$. 

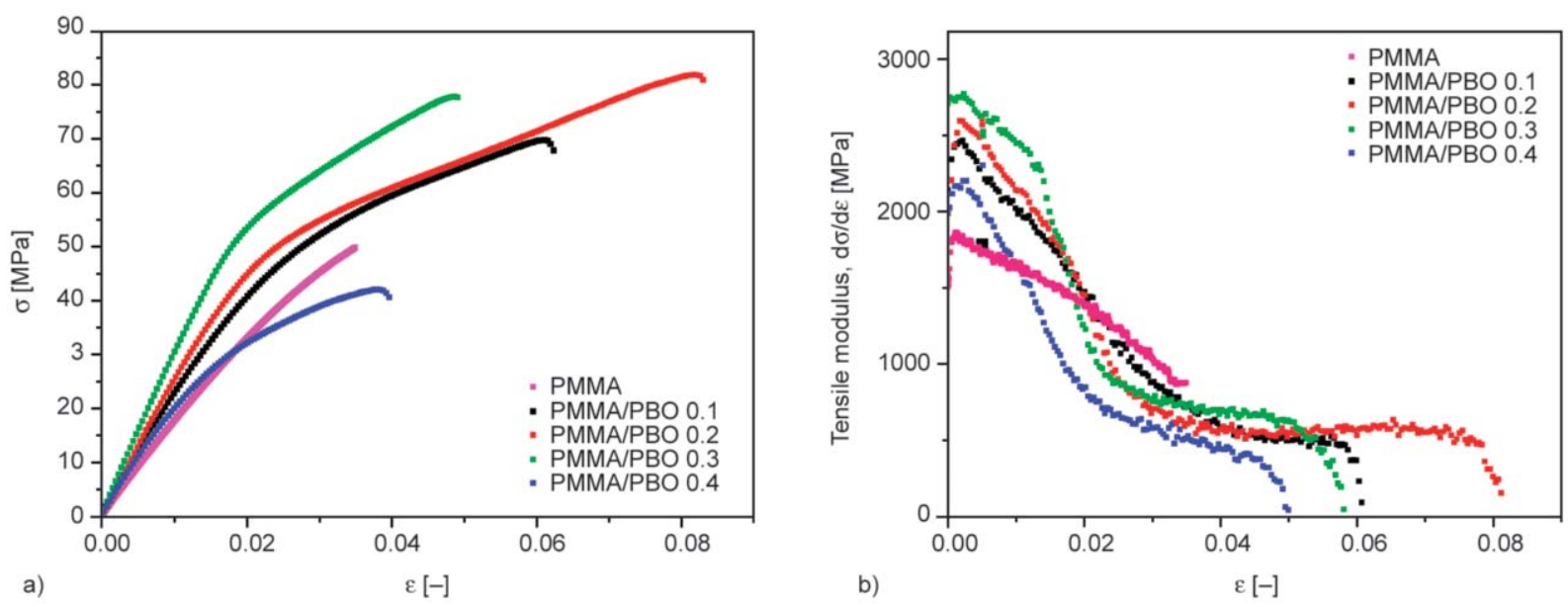

Figure 6. (a) The deformation curves for the PMMA/PBO with varying fiber volume fraction and (b) differentiation of the deformation curves.

These experiments revealed initiation of microcracks, by the homogenously dispersed defects (such as kink bands, fiber ends, loops and/or matrix/fiber interface) at small deformation around $0.75 \%$ randomly throughout the specimen. Up to the strain of $2.80 \%$, these cracks grew in a stable manner while additional micro-cracks were generated in their vicinity, forming bands perpendicular to the loading direction and bridged by the $\mathrm{PBO}$ fiber mesh. This is evidenced by slight curvature on the stress-strain curve. This initiation strain is marked as $\varepsilon_{0}$ and the associated stress as $\sigma_{0}$ representing the conditions for brittle failure of the PMMA/PBO composites without the additional fiber toughening mechanisms (see Figure 5). From the SEM observation (Figure 1d), matrix-fiber interfacial failure is evident and, thus, this mechanisms also occurred at this deformation (most probably from the very small strains). Sufficiently long and entangled fibers are crucial for expanding propagating cracks trough the cracking interface. However, after reaching critical size of the damage zone, a significant drop in stress was observed for brittle glass fibers [38,39] which was not observed in the case of our PMMA/PBO composites (Figure 5, 6). This is most probably caused by an additional deformation mechanism consisting of micro-cracking generating large a number of additional fracture surfaces. Further deformation caused the micro-cracks to open and coalesce into larger ones until the complete failure of the specimen at the strain of approximately $\sim 6 \%$.

Assuming the slope of the $\sigma-\varepsilon$ curve reflects the structural changes in the composite caused by increasing deformation, we differentiated the $\sigma-\varepsilon$ curve and obtained strain dependence of the apparent composite stiffness (Figure 5, 6). The structural changes revealed by CLSM agreed fairly well with the shape of the strain dependence of $d \sigma / d \varepsilon$ (Figure 5). After reaching a critical strain, $\varepsilon_{0}$, slight increase in the slope of modulus curve $(\mathrm{d} \sigma / \mathrm{d} \varepsilon)$ is observed and it is attributed to fiber bridging mechanism as fibers are being stretched. Constant portion of the $\mathrm{d} \sigma / \mathrm{d} \varepsilon$ vs. $\varepsilon$ curve between the $\varepsilon_{0}$ and the onset of rapid stiffness drop during composite failure is attributed to the fiber bridging mechanism as the prevailing deformation process.

This is further supported by the effect of the PBO fiber volume fraction on the shape of the $\mathrm{d} \sigma / \mathrm{d} \varepsilon$ vs. $\varepsilon$ curves (Figure 6). The constant portion of the $\mathrm{d} \sigma / \mathrm{d} \varepsilon$ vs. $\varepsilon$ curve is the largest for the $v_{\mathrm{F}}=0.2$, for which the largest extent of fiber bridging (the widest opened cracks bridged by PBO fibers) was observed (Figure 4$)$ and also the largest ultimate strain $(\varepsilon \sim 8 \%)$ was measured (Figure 6). This unique toughening mechanism is a result of the PBO fiber network delaying the catastrophic failure and contributing to the composite ability to maintain a portion of its load bearing capability at significant structural damage (Figure 5). After reaching the composite failure, only pull-out of the PBO fibers occurred. However, the contribution of this mechanism to the load bearing capacity was negligible.

\subsubsection{Fracture energy}

Our experimental results exhibit direct relationship between the relative fracture energy and the relative strain with the slope of approximately 0.5 (Figure 7a) and, thus, suggest that the fiber toughening is caused mainly by extending the composite's ultimate strain to failure. 

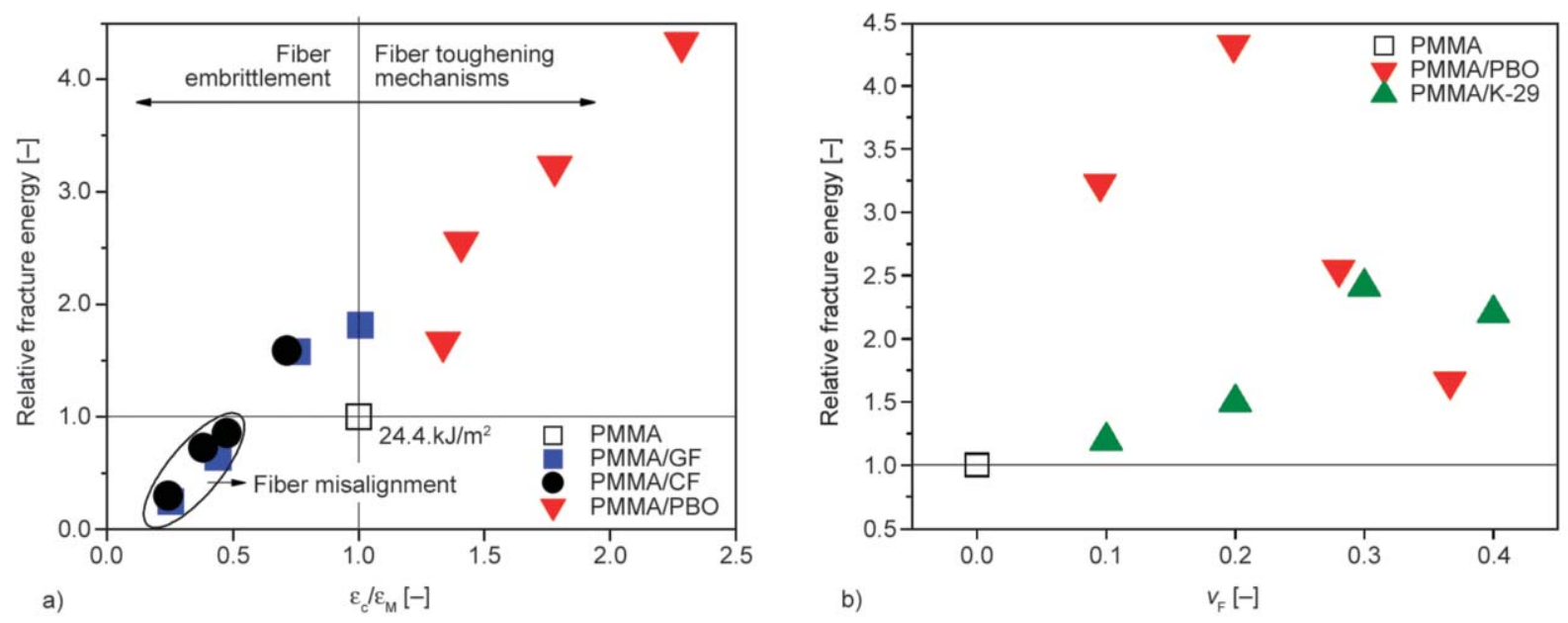

Figure 7. (a) The relative fracture energy as function of relative failure strain. (b) The relative fracture energy as function of the fiber volume fraction for PMMA/PBO and PMMA/Kevlar fibers from ref. [35].

Xiu et al. [58] reported that the addition of $20 \mathrm{vol} \%$ of CF into brittle PLA matrix resulted in 1.7 fold increase in toughness of their binary composites by fiber pull-out. This number is in good correlation with our GF and CF composites at low fiber volume fractions (10-20 vol\%) (Figure 2d). In a previous work by Jancar et al. [35], the fiber deformation and pullout was ascribed to an enhancement of the critical strain energy release rate of a brittle PMMA composite toughened by short low bending modulus Kevlar and poly-vinyl alcohol fibers. Kevlar fibers had a similar length $(3.8 \mathrm{~mm})$ as used PBO fibers. The addition of $20 \mathrm{vol} \%$ of Kevlar fibers increased the fracture energy by factor of 1.5. In order to compare the effectiveness of the crack delocalization and fiber bridging (PBO) versus fiber pull-out mechanisms in Kevlar reinforced composites [35], the relative fracture energy was plotted against the fiber volume fraction (Figure 7b). The results support the superior effectiveness of the homogenization of deformation by entangled and kink banded fiber network (PBO) compared to fiber pull-out mechanism in toughening of the PMMA composite.

A schematic representation of the complex toughening mechanism with the experimental observation in the PMMA/PBO composites is illustrated in Figure 8. Matrix/fiber interface debonds due to a very weak interfacial adhesion and the main crack plane can be deflected into this interface causing the damage zone to expand (Figure 8e). The length of the PBO fibers remains in the order of millimeters after melt processing, thus contribution of this mechanism to the overall fracture energy is significant due to creating large additional fracture surface. Entangled fiber network also contributes to the strain delocalization because single PBO fiber can involve multiple entangling and adjacent fibers relatively far away from the main crack plane [40, 41, 54]. Here, the soft compliant kink bands would be deformed more than the un-deformed remaining portion of the fiber.

Defects such as mechanically deformed kink bands with low stiffness (plus fiber ends, transversely oriented or looped fibers and matrix/fiber interface can contribute similarly) are ideal for stress concentration and crack initiation as fiber network is stretched. The initiation of micro-crack on the kink band observed in the view field of CLSM during tensile test (Figure $8 \mathrm{~b}, 8 \mathrm{c}$ ) further supports this hypothesis. We point out the unique role of this micro-cracking on the soft kink bands during fiber network stretching as a mechanism creating considerably large amount of additional fracture surface. In plastics [59] and fiber reinforced composites [58, 60-62] toughened by rubber particles, various micro-cracking on the soft rubber particles occurs during the loading in the vicinity of propagating crack as mechanism improving the fracture resistance. In the case of PMMA/PBO composites, micro-cracking much farther from the main crack plane is supported also by the loading of the entangled fiber network (stress transfer within fiber network) and the compliance of soft kink bands. Each micro-crack generated on these defects grows further into ordinary crack and the situation is repeated over the whole volume of sample. When compared to rubber toughened plastics employing similar toughening mechanisms via micro-cracking and crack bridging, no significant decrease in the tensile modulus upon addition of PBO fibers into matrix was observed as 


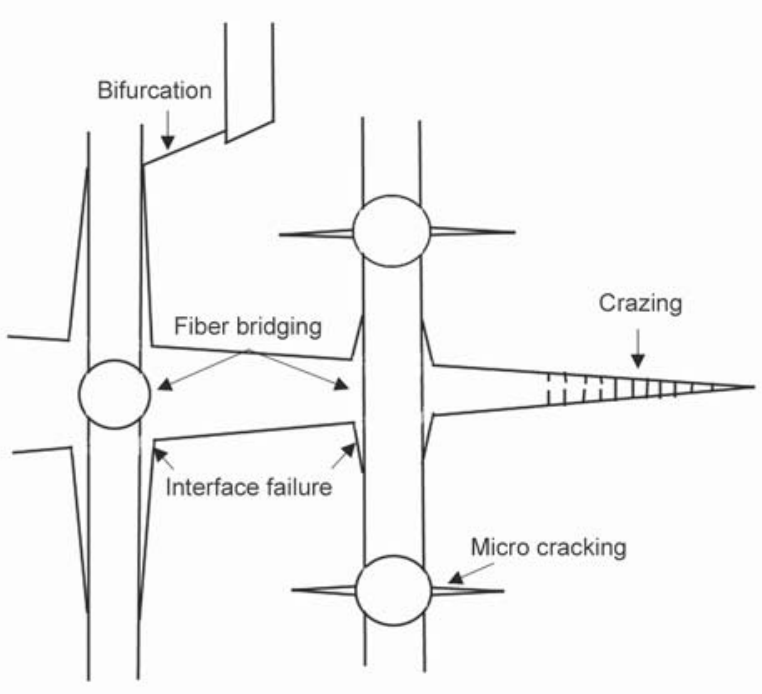

a)

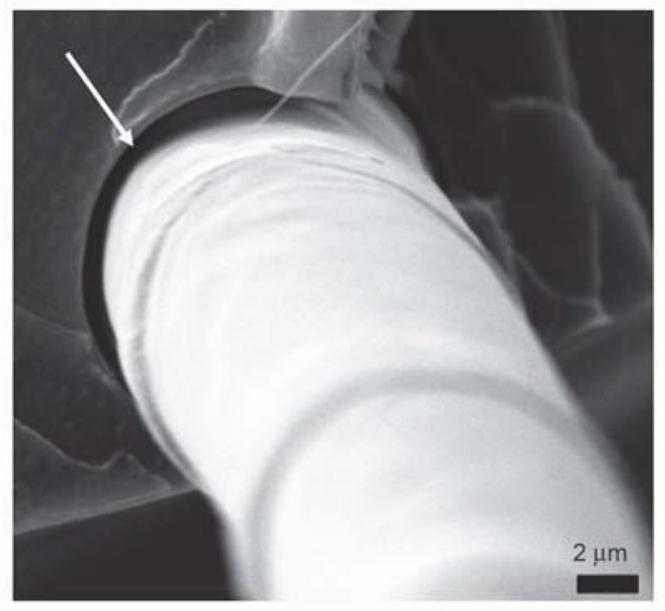

e)

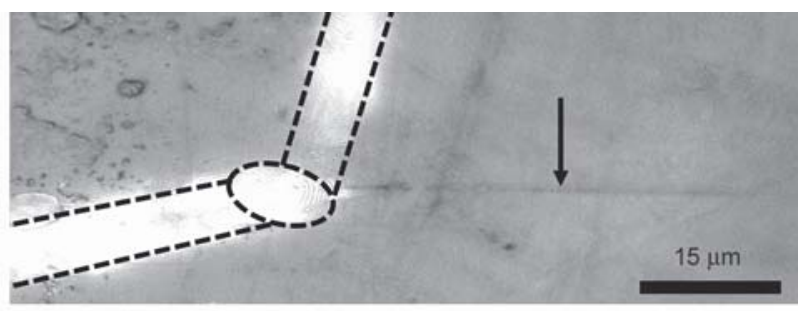

b)

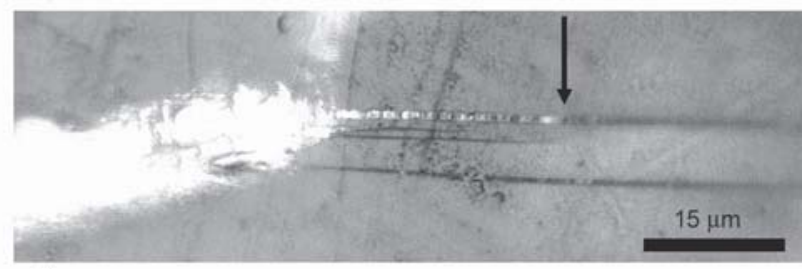

c)
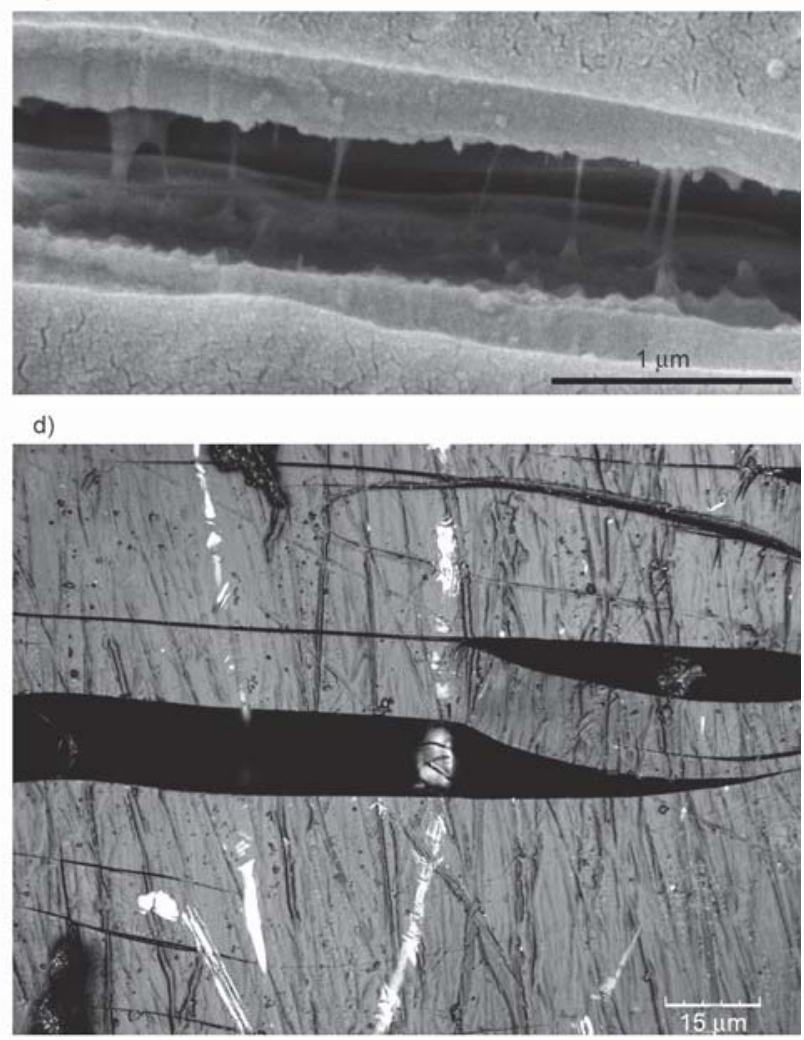

f)

Figure 8. (a) Simplified depiction of propagating crack and toughening mechanisms observed in PMMA/PBO composites (b) Initiation of micro-crack (arrow) on the kink band during stretching of composite with outline of PBO fiber with kink band under the sample surface. (c) Same area at larger strain with visible crazing in the opening crack, scale bar $15 \mu \mathrm{m}$. (d) SEM micrograph of craze fibrils in the proximity of crack tip, scale bar $1 \mu \mathrm{m}$. (e) Matrix/fiber interfacial debonding, scale bar $2 \mu \mathrm{m}$ and (f) crack bridging by PBO fiber.

common drawback of rubber toughening agents [58, $60,61]$.

Both mechanisms (i) expanding of deformation zone via fiber network and (ii) micro-cracking occurs simultaneously and they influence each other. Propagating cracks are bridged by PBO fibers and thus stabilizing their growth and load bearing capability of composite (Figure 8f). After reaching critical strain $\left(\varepsilon_{0}\right)$ this mechanism is dominant while cracks are being opened and fibers are stretched. In addition, crazing behind propagating crack tip was observed via SEM (Figure 8d) and in-situ observation by CLSM (Figure 8b, 8c) during composite loading as first deformation mechanism that is in very proximity of crack tip.

Assuming that the various contributions to the total fracture energy are independent, we prepared a hybrid PMMA/CF/PBO composite containing $10 \mathrm{vol} \%$ 


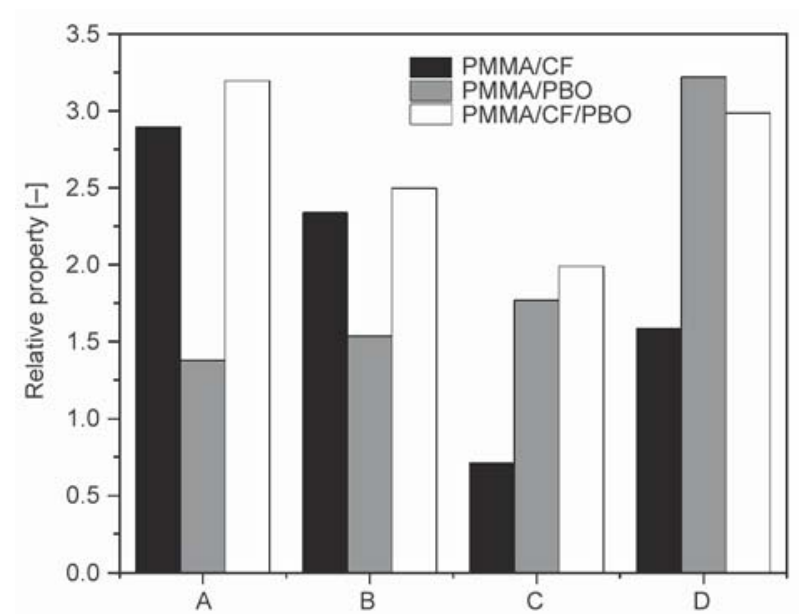

Figure 9. A comparison of changes in (a) tensile modulus, (b) strength, (c) ultimate strain and (d) fracture energy of the PMMA/CF, PMMA/PBO composite containing $10 \mathrm{vol} \%$ of $\mathrm{CF}$ or $\mathrm{PBO}$, respectively and the hybrid PMMA/CF/PBO composite containing $10 \mathrm{vol} \%$ of both $\mathrm{CF}$ and $\mathrm{PBO}$ fibers relative to those for the neat PMMA.

of each fiber type. The substantial increase of both tensile modulus and strength over the values for the neat PMMA has been ascribed solely to the stresstransfer contribution to the CF. The PBO fibers provided toughening mechanisms and as a result, the fracture energy of the hybrid composite increased substantially as compared to both neat PMMA and the PMMA/CF composite (Figure 9). This increase in fracture resistance is not offset by any decrease of other thermo-mechanical properties as often encountered in the case of rubber toughening.

\section{Conclusions}

The addition of the PBO fibers had only marginal effect on the composite stiffness, however, it resulted in a significant enhancement of the ultimate tensile strain, while maintaining load bearing capability of composite and ultimately enhancing fracture energy. The morphology of PBO fibers after melt processing shows large number of kink bands and complicated entangled network. The PBO fibers changed the failure process and causing main crack bifurcation and micro-crack formation away from the main crack plane on the various defects such as mechanical uneffective kink bands. Moreover, the entangled PBO fiber network expanded the damage zone to the whole volume of sample and bridged these microcracks, thus stabilizing their growth and supported load bearing capability. These extrinsic toughening mechanisms were more effective than the fiber pullout observed for the PMMA reinforced with aramid fibers, reported previously. The PBO fibers were also an effective toughness improving additive in the hybrid PMMA/CF/PBO composites. The CF component provided stiffening and strength enhancement via stress transfer while the entangled PBO fiber mesh provided the ultimate strain enhancement. Using the short PBO fibers as a toughening additive may yield SFRT with the desired balance of stiffness, strength and toughness. These lightweight moldable composites can find a wide range of applications, especially in the automotive components aiming both mechanical robustness and toughness.

\section{Acknowledgements}

This research has been financially supported under the grant from the Czech Grant Agency (15-18495S) and under grant from the Brno University of Technology (STI-J-16-3650).

\section{References}

[1] Fu S-Y., Lauke B., Mäder E., Yue C-Y., Hu X.: Tensile properties of short-glass-fiber- and short-carbon-fiberreinforced polypropylene composites. Composites Part A: Applied Science and Manufacturing, 31, 1117-1125 (2000). https://doi.org/10.1016/S1359-835X(00)00068-3

[2] Fu S-Y., Lauke B., Mäder E., Yue C-Y., Hu X., Mai Y-W.: Hybrid effects on tensile properties of hybrid shortglass-fiber-and short-carbon-fiber-reinforced polypropylene composites. Journal of Materials Science, 36, $1243-$ 1251 (2001). https://doi.org/10.1023/A:1004802530253

[3] Laura D. M., Keskkula H., Barlow J. W., Paul D. R.: Effect of glass fiber surface chemistry on the mechanical properties of glass fiber reinforced, rubber-toughened nylon 6. Polymer, 43, 4673-4687 (2002).

https://doi.org/10.1016/S0032-3861(02)00302-6

[4] Lauke B., Fu S-Y.: Strength anisotropy of misaligned short-fibre-reinforced polymers. Composites Science and Technology, 59, 699-708 (1999).

https://doi.org/10.1016/S0266-3538(98)00115-8

[5] Wang H. W., Zhou H. W., Gui L. L., Ji H. W., Zhang X. C.: Analysis of effect of fiber orientation on Young's modulus for unidirectional fiber reinforced composites. Composites Part B: Engineering, 56, 733-739 (2014). https://doi.org/10.1016/j.compositesb.2013.09.020

[6] Ying Z., Wu D., Zhang M., Qiu Y.: Polylactide/basalt fiber composites with tailorable mechanical properties: Effect of surface treatment of fibers and annealing. Composite Structures, 176, 1020-1027 (2017). https://doi.org/10.1016/j.compstruct.2017.06.042 
[7] Curtis P. T., Bader M. G., Bailey J. E.: The stiffness and strength of a polyamide thermoplastic reinforced with glass and carbon fibres. Journal of Materials Science, 13, 377-390 (1978).

https://doi.org/10.1007/BF00647783

[8] Ku H., Wang H., Pattarachaiyakoop N., Trada M.: A review on the tensile properties of natural fiber reinforced polymer composites. Composites Part B: Engineering, 42, 856-873 (2011).

https://doi.org/10.1016/j.compositesb.2011.01.010

[9] Singh T. J., Samanta S.: Characterization of Kevlar fiber and its composites: A review. Materials Today: Proceedings, 2, 1381-1387 (2015).

https://doi.org/10.1016/j.matpr.2015.07.057

[10] Fu S., Yu B., Duan L., Bai H., Chen F., Wang K., Deng H., Zhang Q., Fu Q.: Combined effect of interfacial strength and fiber orientation on mechanical performance of short Kevlar fiber reinforced olefin block copolymer. Composites Science and Technology, 108, 23-31 (2015).

https://doi.org/10.1016/j.compscitech.2015.01.001

[11] Santos P., Pezzin S. H.: Mechanical properties of polypropylene reinforced with recycled-PET fibres. Journal of Materials Processing Technology, 143, 517-520 (2003). https://doi.org/10.1016/S0924-0136(03)00391-1

[12] Yu Z., Wang X., Wu D.: Mechanical properties, impact fracture behavior, and morphology of long-polyimidefiber-reinforced poly(butylene terephthalate) composites. Journal of Composite Materials, 51, 3425-3439 (2017).

https://doi.org/10.1177/0021998316687031

[13] Jiang C., Han E., Wang X., Wu D.: Effect of discontinuous long polyimide fiber on mechanical properties, fracture morphology, and crystallization behaviors of polyamide-6 matrix composites. Journal of Thermoplastic Composite Materials, 31, 223-245 (2018).

https://doi.org/10.1177/0892705717697776

[14] Davies R. J., Eichhorn S. J., Riekel C., Young R. J.: Crystal lattice deformation in single poly ( $p$-phenylene benzobisoxazole) fibres. Polymer, 45, 7693-7704 (2004). https://doi.org/10.1016/j.polymer.2004.08.030

[15] Chae H. G., Kumar S.: Rigid rod polymeric fibers. Journal of Applied Polymer Science, 100, 791-802 (2006). https://doi.org/10.1002/app.22680

[16] Hu X-D., Jenkins S. E., Min B. G., Polk M. B., Kumar S.: Rigid-rod polymers: Synthesis, processing, simulation, structure, and properties. Macromolecular Materials and Engineering, 288, 823-843 (2003).

https://doi.org/10.1002/mame.200300013

[17] Kitagawa T., Ishitobi M., Yabuki K.: An analysis of deformation process on poly- $p$-phenylenebenzobisoxazole fiber and a structural study of the new high-modulus type PBO HM+ fiber. Journal of Polymer Science Part B: Polymer Physics, 38, 1605-1611 (2000).

https://doi.org/10.1002/(SICI)10990488(20000615)38:12<1605::AID-POLB50>3.0.CO;2-Z
[18] Kitagawa T., Yabuki K., Young R. J.: An investigation into the relationship between processing, structure and properties for high-modulus PBO fibres. Part 1. Raman band shifts and broadening in tension and compression. Polymer, 42, 2101-2112 (2001). https://doi.org/10.1016/S0032-3861(00)00571-1

[19] Wegst U. G. K., Bai H., Saiz E., Tomsia A. P., Ritchie R. O.: Bioinspired structural materials. Nature Materials, 14, 23-36 (2015). https://doi.org/10.1038/nmat4089

[20] Ritchie R. O.: Mechanisms of fatigue-crack propagation in ductile and brittle solids. International Journal of Fracture, 100, 55-83 (1999).

https://doi.org/10.1023/A:1018655917051

[21] Lampman S.: Characterization and failure analysis of plastics. ASM International, Materials Park (2003).

[22] Luo W-B., Yang T-Q., Wang X-Y.: Time-dependent craze zone growth at a crack tip in polymer solids. Polymer, 45, 3519-3525 (2004).

https://doi.org/10.1016/j.polymer.2004.03.014

[23] Luo W., Wang C., Zhao R., Tang X., Tomita Y.: Creep behavior of poly(methyl methacrylate) with growing damage. Materials Science and Engineering: A, 483484, 580-582 (2008).

https://doi.org/10.1016/j.msea.2006.07.176

[24] Basu S., Mahajan D. K., Van der Giessen E.: Micromechanics of the growth of a craze fibril in glassy polymers. Polymer, 46, 7504-7518 (2005). https://doi.org/10.1016/j.polymer.2005.05.148

[25] Wu S., Ladani R. B., Zhang J., Bafekrpour E., Ghorbani K., Mouritz A. P., Kinloch A. J., Wang C. H.: Aligning multilayer graphene flakes with an external electric field to improve multifunctional properties of epoxy nanocomposites. Carbon, 94, 607-618 (2015).

https://doi.org/10.1016/j.carbon.2015.07.026

[26] Huguet S., Godin N., Gaertner R., Salmon L., Villard D.: Use of acoustic emission to identify damage modes in glass fibre reinforced polyester. Composites Science and Technology, 62, 1433-1444 (2002).

https://doi.org/10.1016/S0266-3538(02)00087-8

[27] Zhuang X., Yan X.: Investigation of damage mechanisms in self-reinforced polyethylene composites by acoustic emission. Composites Science and Technology, 66, 444-449 (2006).

https://doi.org/10.1016/j.compscitech.2005.07.013

[28] Fu S-Y., Mai Y-W., Lauke B., Yue C-Y.: Synergistic effect on the fracture toughness of hybrid short glass fiber and short carbon fiber reinforced polypropylene composites. Materials Science and Engineering: A, 323, 326-335 (2002).

https://doi.org/10.1016/S0921-5093(01)01383-1

[29] Tanaka K., Kitano T., Egami N.: Effect of fiber orientation on fatigue crack propagation in short-fiber reinforced plastics. Engineering Fracture Mechanics, 123, 44-58 (2014).

https://doi.org/10.1016/j.engfracmech.2014.03.019 
[30] Norman D. A., Robertson R. E.: The effect of fiber orientation on the toughening of short fiber-reinforced polymers. Journal of Applied Polymer Science, 90, 2740-2751 (2003).

https://doi.org/10.1002/app.12913

[31] Wu Z. J., Davies J. M.: Coupling effect of interphase and fibre-bridging on the toughness of FRP. Composites Part A: Applied Science and Manufacturing, 36, 257-262 (2005).

https://doi.org/10.1016/j.compositesa.2004.06.015

[32] Wu Z. J., Davies J. M.: Effect of interphase on fibrebridging toughness of a unidirectional FRP composite thin plate. Composite Structures, 69, 510-515 (2005). https://doi.org/10.1016/j.compstruct.2004.08.008

[33] Ladani R. B., Wu S., Kinloch A. J., Ghorbani K., Zhang J., Mouritz A. P., Wang C. H.: Improving the toughness and electrical conductivity of epoxy nanocomposites by using aligned carbon nanofibres. Composites Science and Technology, 117, 146-158 (2015).

https://doi.org/10.1016/j.compscitech.2015.06.006

[34] Friedrich K.: Microstructural efficiency and fracture toughness of short fiber/thermoplastic matrix composites. Composites Science and Technology, 22, 43-74 (1985).

https://doi.org/10.1016/0266-3538(85)90090-9

[35] Jancar J., Hynstova K., Pavelka V.: Toughening of denture base resin with short deformable fibers. Composites Science and Technology, 69, 457-462 (2009). https://doi.org/10.1016/j.compscitech.2008.11.014

[36] Karger-Kocsis J., Yuan Q., Czigany T.: Assignment of acoustic emission to the failure sequence and damage zone growth in glass fiber strand mat-reinforced structural nylon RIM composites. Polymer Bulletin, 28, 717-723 (1992).

https://doi.org/10.1007/BF00295978

[37] Karger-Kocsis J.: Fracture mechanical characterization and damage zone development in glass fiber mat-reinforced thermoplastics. Polymer Bulletin, 31, 235-241 (1993). https://doi.org/10.1007/BF00329971

[38] Karger-Kocsis J., Czigany T.: Fracture behaviour of glass-fibre mat-reinforced structural nylon RIM composites studied by microscopic and acoustic emission techniques. Journal of Materials Science, 28, 2438 2448 (1993). https://doi.org/10.1007/BF01151677

[39] Karger-Kocsis J., Fejes-Kozma Zs.: Failure mode and damage zone development in a GMT-PP by acoustic emission and thermography. Journal of Reinforced Plastics and Composites, 13, 768-792 (1994). https://doi.org/10.1177/073168449401300901

[40] Karger-Kocsis J., Harmia T., Czigány T.: Comparison of the fracture and failure behavior of polypropylene composites reinforced by long glass fibers and by glass mats. Composites Science and Technology, 54, 287-298 (1995).

https://doi.org/10.1016/0266-3538(95)00068-2
[41] Lindhagen J., Berglund L.: Microscopical damage mechanisms in glass fiber reinforced polypropylene. Journal of Applied Polymer Science, 69, 1319-1327 (1998). https://doi.org/10.1002/(SICI)10974628(19980815)69:7<1319::AID-APP6>3.0.CO;2-H

[42] Friedrich K., Almajid A. A.: Manufacturing aspects of advanced polymer composites for automotive applications. Applied Composite Materials, 20, 107-128 (2013). https://doi.org/10.1007/s10443-012-9258-7

[43] Gao G., Zhang Z., Li X., Meng Q., Zheng Y.: An excellent ablative composite based on PBO reinforced EPDM. Polymer Bulletin, 64, 607-622 (2010). https://doi.org/10.1007/s00289-009-0204-2

[44] Chau C. C., Thomsen M. H., St Jeor V. L.: Direct observation of compressive deformation of PBO fibre in the SEM. Journal of Materials Science, 27, 5645-5652 (1992). https://doi.org/10.1007/BF00541637

[45] Chau C. C., Blackson J., Im J.: Kink bands and shear deformation in polybenzobisoxazole fibres. Polymer, 36, 2511-2516 (1995). https://doi.org/10.1016/0032-3861(95)91195-D

[46] Kobayashi H., McDonough W. G., Dunkers J. P., Wight S. A., Lee H. J., Kim J. H., Forster A. L., Rice K. D., Holmes G. A.: X-ray scattering study on the damage in fibers used in soft body armor after folding. Polymer Composites, 33, 803-811 (2012). https://doi.org/10.1002/pc.22210

[47] Fu S-Y., Lauke B., Mai Y-W.: Major factors affecting the performance of short fibre reinforced polymers. in 'Science and engineering of short fibre reinforced polymer composites' (eds.: Fu S. Y., Lauke B., Mai Y-W.) Woodhead, Cambridge, Vol 1, 29-58 (2009). https://doi.org/10.1533/9781845696498.29

[48] Mortazavian S., Fatemi A.: Effects of fiber orientation and anisotropy on tensile strength and elastic modulus of short fiber reinforced polymer composites. Composites Part B: Engineering, 72, 116-129 (2015). https://doi.org/10.1016/j.compositesb.2014.11.041

[49] Hu C., Wang F., Yang H., Ai J., Wang L., Jing D., Shao L., Zhou X.: Preparation and characterisation of poly p-phenylene-2,6-benzobisoxazole fibre-reinforced resin matrix composite for endodontic post material: A preliminary study. Journal of Dentistry, 42, 1560-1568 (2014). https://doi.org/10.1016/j.jdent.2014.10.007

[50] Zhang X., Chen P., Han D., Yu Q., Ding Z., Zhu X.: Effect of thermoplastic coating on interfacial adhesion of oxygen-plasma-pretreated PBO/PPESK composites. Applied Surface Science, 266, 110-117 (2013). https://doi.org/10.1016/j.apsusc.2012.11.108

[51] Liu D., Chen P., Yu Q., Ma K., Ding Z.: Improved mechanical performance of $\mathrm{PBO}$ fiber-reinforced bismaleimide composite using mixed $\mathrm{O}_{2} / \mathrm{Ar}$ plasma. Applied Surface Science, 305, 630-637 (2014). https://doi.org/10.1016/j.apsusc.2014.03.150 
[52] So C. L., Young R. J.: Interfacial failure in $\operatorname{poly}(p-$ phenylene benzobisoxazole) (PBO)/epoxy single fibre pull-out specimens. Composites Part A: Applied Science and Manufacturing, 32, 445-455 (2001). https://oi.org/10.1016/S1359-835X(00)00106-8

[53] Zhang Z. F., Hu X.: The effect of addition of $\mathrm{SiO}_{2}$ on the mechanical properties of PBO-fiber-filled HDPE composites. Mechanics of Composite Materials, 51, 377-382 (2015).

https://doi.org/10.1007/s11029-015-9508-5

[54] Sun H., Hu J., Bai X., Zheng Z., Feng Z., Ning N., Zhang L., Tian M.: Largely improved toughness of poly (lactic acid) by unique electrospun fiber network structure of thermoplastic polyurethane. Polymer Testing, 64, 250-253 (2017).

https://doi.org/10.1016/j.polymertesting.2017.10.012

[55] Tucker C. L., Liang E.: Stiffness predictions for unidirectional short-fiber composites: Review and evaluation. Composites Science and Technology, 59, 655-671 (1999).

https://doi.org/10.1016/S0266-3538(98)00120-1

[56] Hine P. J., Lusti H. R., Gusev A. A.: Numerical simulation of the effects of volume fraction, aspect ratio and fibre length distribution on the elastic and thermoelastic properties of short fibre composites. Composites Science and Technology, 62, 1445-1453 (2002). https://doi.org/10.1016/S0266-3538(02)00089-1
[57] Halpin Affdl J. C., Kardos J. L.: The Halpin-Tsai equations: A review. Polymer Engineering and Science, 16, 344-352 (1976).

https://doi.org/10.1002/pen.760160512

[58] Xiu H., Qi X., Liu Z., Zhou Y., Bai H., Zhang Q., Fu Q.: Simultaneously reinforcing and toughening of polylactide/carbon fiber composites via adding small amount of soft poly(ether)urethane. Composites Science and Technology, 127, 54-61 (2016). https://doi.org/10.1016/j.compscitech.2016.02.025

[59] Zotti A., Zuppolini S., Zarrelli M., Borriello A.: Fracture toughening mechanisms in epoxy adhesives. in 'Adhesives - Applications and properties' (ed.: Rudawska A.) InTech, Rijeka, 237-269 (2016). https://doi.org/10.5772/65250

[60] Ozdemir N. G., Zhang T., Hadavinia H., Aspin I., Scarpa F.: Glass fibre reinforced polymer composites toughened with acrylonitrile butadiene nanorubber. Composites Part B: Engineering, 88, 182-188 (2016). https://doi.org/10.1016/j.compositesb.2015.09.004

[61] Ozdemir N. G., Zhang T., Aspin I., Scarpa F., Hadavinia H., Song Y.: Toughening of carbon fibre reinforced polymer composites with rubber nanoparticles for advanced industrial applications. Express Polymer Letters, 10, 394-407 (2016).

https://doi.org/10.3144/expresspolymlett.2016.37

[62] Kim J. R., Kim J. J.: Epoxy resins toughened with surface modified epoxidized natural rubber fibers by onestep electrospinning. Materials, 10, 464/1-464/13 (2017). https://doi.org/10.3390/ma10050464 